\title{
No Belief is Contingently True
}

\author{
Ari Maunu \\ University of Turku, Finland
}

Abstract

It is commonly held, plausibly, that many true beliefs are true only contingently, that is, are actually true (or true with respect to the actual world) but would be false were the world in some relevant ways otherwise (i.e. are false with respect to some other possible worlds). However, a radically different approach, according to which no belief is contingently true, is entirely defensible. The key point in this alternative approach is that each belief concerns the world in which the believer is (or would be) situated, which makes it the case that, say, the actual belief that Kofi Annan is not bald is different from the belief, in any other world, that Kofi Annan is not bald. This difference is further backed up by considerations related to disagreement between believers, and to knowledge. The most important objection to this alternative approach is that it cannot be right since it makes all true beliefs necessarily true. It will be shown, as a reply to this objection, that under this alternative approach it can still be said truly, for instance, that Annan is not bald but could have been so.

\section{No Belief is Contingently True}

0 . Meaning by the notion of a belief's being contingently true that it is true actually, or in the actual circumstance or world, but is not necessarily true, i.e. is not true in some other possible world (alternative to the actual one), I think there is a natural sense in which it may be said that no belief is contingently true. This, of course, goes against the customary approach, according to which many true beliefs are only contingently true. The purpose of this paper is to bring into focus the basic assumptions of this received 
view by suggesting a coherent and justified alternative approach according to which, to repeat, there are no contingently true (nor false) beliefs.

1. Beliefs-in the sense of what is believed-are standardly regarded as determinate or fixed with respect to moments of time. The basic rationale behind this view is, it seems, that when somebody believes, for example, that Kofi Annan is not bald, he or she does not believe that Annan fails to be bald irrespective of a moment of time, but believes that Annan is not bald at some definite time. In statements expressing a belief the indication of time is either explicit, as in "Kofi Annan was not bald in his fiftieth birthday", or implicit, as in "Kofi Annan is not bald"-what is normally meant by this latter is, "Kofi Annan is presently not bald." (Below, I often leave the indication of time as implicit.)

2. It will be argued that it is entirely natural to regard beliefs (in the sense of objects of belief) as fixed not only with respect to time but also with respect to possible worlds. Kofi Annan is not bald in the actual world-and I truly believe, in the actual world, that Kofi Annan is not bald. It is then commonly held that this belief is contingent in the sense that it - the very same beliefwould be false if the circumstances were appropriately different, namely, if Kofi Annan were bald. I shall challenge this claim of the sameness of these beliefs and show that we have a good reason to say that the belief in (or, with respect to) the actual world, $\alpha$, that Kofi Annan is not bald is in fact distinct from the belief in (or, with respect to) some other world, $w$, that Kofi Annan is not bald.

When I believe that Kofi Annan is not bald what is it that I believe? Is it what might be called a contextless belief, the belief which I might express to myself by the words "No matter what the circumstances, Kofi Annan is not bald?" No. What I believe is something fully determinate which may be expressed by something like the following:

(1) Presently, here, as this world now stands, Kofi Annan is not bald. 
Now, I am situated in the actual world $\alpha$ and I believe, truly, what is expressed in (1). Of course, I would probably not say (1) in full, but only the part "Kofi Annan is not bald"-however, something like what is expressed in (1) is what I really believe, when my belief is more fully articulated. Let me then be in the world (circumstance) $w$, where Kofi Annan is bald. My false belief in $w$ that Kofi Annan is not bald is again expressible, with respect to $w$, by (1). Is this $w$-belief, as we may call it, the same belief as the corresponding $\alpha$-belief? I do not think so, for the false belief in $w$ may also be described by the words, "Presently, here, as this world now stands, Kofi Annan is not bald"-(1) contains indexical expressions "presently," "here," "this world," "now," and accordingly, the belief in the actual world $\alpha$ that Kofi Annan is not bald concerns the actual world $\alpha$ (that is, the way the world actually is), while the belief with respect to $w$ expressed by "Kofi Annan is not bald" concerns in the same way the world $w$. In conclusion, beliefs are to be regarded as fixed with respect to time and possible world.

3. It is standardly said that some beliefs are true and some false (and, perhaps, that some are neither true nor false; we may, without affecting the substance of this paper, leave aside this possibility). Accordingly, we may say that a belief is a bearer of a truth value.

4. It follows that a belief, i.e. an object of belief, is temporally and alethically stable with respect to its truth value: No belief changes its truth value through moments of time or through possible worlds. For in $\$ 1$ above we saw that what is believed involves time and in $\$ 2$ that it involves a possible world: What $I$ believe is that Annan is not bald at $t$ in the actual world. In \$3, in turn, was stated the usual view that what may be believed are bearers of truth values-in our example case we have the belief expressed by:

(2) Annan is actually not bald at $t$.

This belief is true and there is no possible world in which it is not true: There is no world $w$ such that what we express by (2) is not 
true with respect to $w .{ }^{1}$ Accordingly, my belief is not contingent. (Any belief that is claimed to be contingent is in the similar manner seen not to be so.)

5. What was put forward in $\$ \$ 1-2$ above may be criticized as follows: It is not the case that beliefs must be construed as temporally stable (and still less as alethically stable), for there is nothing intrinsically wrong in the account that (empirical) statements and beliefs are something the truth value of which changes with time-which is what Aristotle influentially ${ }^{2}$ puts forward in Categories:

For the same statement [logos] seems to be both true and false. Suppose, for example, that the statement that somebody is sitting is true; after he has got up this same statement will be false. Similarly with beliefs [doxa]. Suppose you believe truly that somebody is sitting; after he has got up you will believe falsely if you hold the same belief about him. ${ }^{3}$

Furthermore (the critic adds), Arthur Prior ${ }^{4}$ and others have developed quite respectable tense logics, which deal with temporally indefinite propositions in statements such as "The proposition $p$ is true now but will be false in the future" (e.g. "The proposition that Annan is not bald is true now but will be false").

There is indeed nothing intrinsically wrong in such a treatment of temporally indefinite "propositions"-but they will not do, it seems to me, as items that are believed. Arguments against "unstable beliefs" may be derived by considering, for example, disagreement and knowledge. It is central to our conception of beliefs that they can be disagreed upon and debated over. If my present true belief that Kofi Annan is not bald is shown "to be false in the future" by some other person's true belief, in 2005, that Annan is bald, we should say that I and that other person disagree upon Annan's baldness, in the sense that we could, at least in 2005, debate over whether my 2003-belief or his or her 2005-belief is true. Clearly, this is absurd: there is nothing here to debate over, and no disagreement. Also, change of mind is a kind 
of disagreement, namely, disagreement with one's earlier self; if then $I$ am that "other person" in 2005 and we say that "that same 2003-belief will be false," it should be the case that I have, by 2005, changed my mind about my 2003 verdict about Annan's baldness, which, however, clearly need not be the case.

Considering then knowledge, I certainly do not lose the knowledge I have now, in 2003, that Annan is not bald, if Annan becomes bald in the future: my knowing, in 2005 (say), that Annan is bald does not in any way concern my presently knowing that he is not bald. Thus, anybody who, despite the argument from disagreement just given, still insists that a belief I have now "may be false in the future," must reject the traditional and extremely plausible assumption that what is known is also believed; for if what I know in 2003 and 2005 is different but what I believe at these times is the same, it follows that objects of belief are distinct from pieces of knowledge: Only the latter are steadily true.

Similar arguments apply to the alethic case. For instance, supposing that somebody in some possible world believes that Kofi Annan is bald, it certainly does not seem plausible to hold that I disagree with him about something in believing, right now, that Annan is not bald: His belief concerns his world and mine mine, and, accordingly, there would be no common ground for a "transworld debate."

6. A closely related criticism of the view propounded abovethat a true belief is fixedly true-is that it seems, especially in the alethic case, to contravene our common way of speaking, for the following is an entirely natural thing to say:

A belief that is true in some circumstance may be false in others.'

For example, the selfsame true belief that Kofi Annan is not bald would be false if Kofi Annan were bald (or so it is said). Thus, it seems evident-against the approach I have tried to justify - that beliefs are not stable over worlds (nor over instants of time?) with respect to truth value. This gives considerable support to the usual view involving unstability: at least some 
beliefs, it seems, are unstable (at least with respect to possible worlds).

Nevertheless, I think we should not say that the items that are believed (i.e. the items that are capable of having a truth value) are unstable: As already argued above, it is not the same belief"same" in the sense of numerical identity-that is true in some worlds and false in others; instead, numerically the same belief retains its truth value through worlds as well as through moments of time, or, more accurately, the truth value of a belief is fixed (both temporally and alethically). To be sure, we may call the $\alpha$ belief and the $w$-belief that Kofi Annan is not bald nominally the same belief, or regard these beliefs as being of the same kind ${ }^{6}-$ but under the approach propounded and justified above, we should not regard these as numerically the same belief. To say that an $\alpha$ belief is numerically the same belief as the corresponding $w$-belief is like saying that since the present Dalai Lama is the present secretary general of the United Nations in the world $u$, the present secretary general in the actual world, viz. Kofi Annan, is numerically the same as the actual present Dalai Lama.

As indicated above, a belief, or at least what might be called an empirical or indexical belief, always contains, however implicitly, a reference to the possible world the believer is situated in; and this world is part of the subject matter of what he or she believes. The believer most certainly does not have a contextless belief of the sort expressed by "Kofi Annan is not bald in a world _," for such a contextually indeterminate item does not amount to a definite object of belief at all. In short, an empirical belief concerns in part the world, or, in other words, the world is a part of the subject matter of an empirical belief. In terms of the analogy used above, just as we can say that Kofi Annan has in $\alpha$ the same position as the Dalai Lama has in $u$, but not of course that Annan is numerically the same as the Dalai Lama, we can say that the belief with respect to $\alpha$ that Kofi Annan is not bald is nominally the same or same in kind as the belief with respect to $w$ that Kofi Annan is not bald, but not that it is numerically the same belief.

In the interest of being more precise, let us apply a Fregean approach, extended to possible worlds, and say that "Annan $(a)$ is 
actually not bald $(B)$," or "Annan is not $\alpha$-bald", or, formally, " $\sim B^{\alpha}(a)$," names a truth value and expresses a belief. Then $\sim B^{x}(a)$, where " $x$ " indicates an argument-place, may be regarded as a function from possible worlds to truth values ${ }^{7}$ and what " $\sim B^{x}(a)$ " expresses is an "incomplete belief." Then the belief expressed by " $\sim B^{\alpha}(a)$ " is true (i.e. " $\sim B^{\alpha}(a)$ " names the True) but the belief expressed by " $\sim B^{w}(a)$ " is false, for some world $w$. What is here the same, corresponding to the phrase "same in kind" is the function $\sim B^{x}(a)$, or, perhaps more properly, the function expressed in " $\sim B^{x}(a)$ ", which in itself, due to its indefiniteness, is not a sort of entity that can serve as an item that may be believed (as I argued above).

7. The criticism that may appear as decisive is that the present approach leaves no room for contingency; for it makes, it seems, all true beliefs necessarily true (and all false beliefs necessarily false). My reply is that although the belief I express by "Kofi Annan is not bald now" is noncontingently true, it could have been the case that Kofi Annan is now bald. ${ }^{8}$ For when I truly utter, "Annan is not bald," I, as indicated above, mean, "Annan is actually not bald now" (or, "Annan is not bald now in the actual world")this is not in the least in contradiction with there being possible worlds in which Annan is bald now. That is, "Annan is not bald in the actual world but he is bald in some other possible world," is unproblematically a true statement (even though somewhat technical). Here the first conjunct is nevertheless noncontingent (since there is no world in which Annan is actually bald, or $\alpha$ bald, for Annan's being actually nonbald is a fixed truth). ${ }^{10}$

Still, it may be insisted that "noncontingently true" just means "necessarily true" and thus if the belief expressed by "Kofi Annan is not bald" is noncontingently true it is by the same token necessarily true. To this it could be said that, strictly speaking, this is not the case, for there is a simple general distinction between constancy and fixedness: For example, construing $x^{2}+1>0$ as a function from (real) numbers to truth values, we may say that this is constantly true since it returns the True for every number, i.e. $\left(x^{2}+1>0\right)$ holds for good. In contrast, e.g. $3^{2}+1>0$, not being a function at all, is fixedly true (or true simpliciter), and the question 
whether it is true for every number is a spurious one; but if it is insisted the we should answer this question, we might say that $3^{2}+1>0$ is only derivatively constantly true (since, admittedly, $\left(3^{2}+1>0\right)$ is true, even though the quantification is purposeless). When applied to temporality this distinction amounts to that between timelessness (in one understanding) and sempiternity (or "alwaysness"); e.g. "Kofi Annan is not bald now" is timelessly (fixedly) true and only derivatively sempiternally (constantly) true-the item of which we may in the proper or strict sense ask, whether it is constantly true or true at all times, may be expressed by "Kofi Annan is not bald at the time _" (leaving here possible worlds aside, or, rather, regarding the world as given). Thus, even though it must be admitted that "Kofi Annan is not bald now" is true at all times (constantly, always, sempiternally true), this alwaysness is of bogus sort, entirely subordinate to timelessness (fixedness). Similarly, there is a clear distinction between constancy as omniworldness and fixedness as "worldlessness." On the present view the entity that may genuinely be said to be necessarily true (i.e. in the sense of omniworldness) is something like the function expressed in " $\sim B^{x}(a)$ ", and this is different from what may be said to be fixedly true or true simpliciter (i.e. is different from what may be believed). "Entities that may serve as bearers of truth values (i.e. beliefs) are different in kind from those incomplete entities to which alethic notions such as necessarily true and possibly true (in the proper sense) relate. In sum, it is not implausible to hold that although all true beliefs are noncontingently true, they are not strictly speaking necessarily true, but only fixedly true: ${ }^{12}$ True beliefs (as well as false beliefs, of course) are true (false) simpliciter. ${ }^{13}$

Notes

1. This view is advanced also by $A$. Plantinga and P. Kitcher (among others). See Plantinga, The Nature of Necessity (Oxford: Oxford University Press, 1974), pp. 62f.; Kitcher, "Apriority and Necessity," Australasian Journal of Philosophy 58 (1980), pp. 94-5, 99. 
2. See G. Nuchelmans, Theories of Proposition: Ancient and Medieval Conceptions of the Bearers of Truth and Falsity (Amsterdam: North-Holland, 1973).

3. Aristotle, Categories 5 (4a23-8).

4. A. N. Prior, Time and Modality (Oxford: Oxford University Press, 1957).

5. Or: "This (same) belief that is actually true would be false if the circumstances were different."

6. It is surely no news that in ordinary speech we often use words like "same" and "identical" in senses other than numerical identity, e.g. in senses "same in kind" and "of the same type". If I see a copy of The Nature of Necessity I may say, "I have this same book also at home".

7. $\sim B^{x}(a)$ is in fact what is often called Carnapian intension, and, by some, even "meaning".

8. To take another example, even though my statement "I am here now" expresses a noncontingent truth, I could be elsewhere now.

9. Or, formally, " $\sim B^{\alpha}(a) \& \exists x B^{x}(a)$ ", where the quantification ranges over possible worlds (alternative to $\alpha$ ).

10. In the similar vein, the possible objection that we normally view "It is true that $p$ " as a logical consequence of "It is necessary that $p$ " is answered by pointing out that on the present approach the former is " $p$ ", which indeed follows logically from the latter, which is " $x p$ " (where the quantification is, again, over possible worlds).

11. Again, even though it is permitted to quantify, say, $\sim B^{\alpha}(a)$ universally (with respect to worlds), to yield " $\sim B^{\alpha}(a)$, this quantification is entirely spurious. In Frege's terminology, necessity (in the sense of omniworldness) is a second-level Begriff, not applicable to a truth value, but only to something incomplete (such as $\sim B^{x}(a)$ ) - just like the universality represented by the normal universal quantifier is a secondlevel Begriff applicable to a first-level Begriff such as If $x$ is a human being, $x$ is mortal.

12. I thus disagree with Plantinga, who in connection with similar considerations holds that world-indexed truths (true beliefs) are necessarily true (and that world-indexed properties such as $\alpha$-baldness are essential properties) - in my view the necessity (and essentiality) are here only of bogus sort. See Plantinga, op. cit., pp. 63f.

13. I thank an anonymous referee of Auslegung for comments and suggestions which helped to improve the exposition of the paper. 